\title{
IFNAR1 gene polymorphism associated with chronic hepatitis $B$ virus infection in a Thai population
}

\author{
Sudtida Phuengwas ${ }^{\mathrm{a}}$, Vipa Hongtrakul ${ }^{\mathrm{b}}$, Nattiya Hirankarn ${ }^{\mathrm{c}}$, Pisit Tangkijvanich ${ }^{\mathrm{d}}$, \\ Chetsada Pothiratana ${ }^{\mathrm{a}}$, Ingorn Kimkong, ${ }^{\mathrm{a}, \mathrm{e}, *}$ \\ a Department of Microbiology, Faculty of Science, Kasetsart University, Bangkok 10900 Thailand \\ b Department of Genetics, Faculty of Science, Kasetsart University, Bangkok 10900 Thailand \\ c Centre of Excellence in Immunology and Immune Mediated Diseases, Department of Microbiology, \\ Faculty of Medicine, Chulalongkorn University, Bangkok 10330 Thailand \\ ${ }^{d}$ Research Unit of Hepatitis and Liver Cancer, Department of Biochemistry, Faculty of Medicine, \\ Chulalongkorn University, Bangkok 10330 Thailand \\ e Centre for Advanced Studies in Tropical Natural Resources, \\ National Research University-Kasetsart University, Kasetsart University, Bangkok 10900 Thailand
}

*Corresponding author, e-mail: fsciiok@ku.ac.th

Received 22 Sep 2014

Accepted 5 Feb 2015

\begin{abstract}
Hepatitis B virus (HBV) infection is the most common cause of chronic hepatitis. Some patients go on to develop liver cirrhosis and hepatocellular carcinoma (HCC). Genetics constitutes an important factor in the pathogenesis of chronic HBV. We therefore investigated the effect of single nucleotide polymorphisms (SNPs) of type I IFN receptor 1 (IFNAR1) gene on chronic HBV infection in Thais. Three SNPs (rs2843710, rs2257167, and rs17875871 harbouring a 4-bp insertion/deletion, a G-568C, and a G19158C substitution, respectively) of the IFNAR1 gene were determined in 567 subjects including 128 chronic HBV patients with HCC, 127 chronic HBV patients without HCC, 176 individuals with self-limited HBV infection, and 136 healthy controls. The polymerase chain reaction-restriction fragment length polymorphism method was used to analyse rs2843710 and rs2257167 SNPs. For rs17875871, a PCRsingle strand conformation polymorphism method was applied to genotype this SNP. The results showed a relationship between the GG genotype of rs2843710 (G-568C) with a protective effect on chronic HBV infection when compared to $\mathrm{GC}$ and CC genotypes (OR $=0.50, p=0.022$ ). For the rs2257167 (G19158C), the G allele was significantly associated with a susceptibility to chronic HBV infection as compared to healthy individuals ( $\mathrm{OR}=1.44, p=0.017$ ). The effect of the $\mathrm{G}$ allele was similar to that of the autosomal dominant in comparison between GG and GC genotypes with CC genotype ( $\mathrm{OR}=1.83, p=0.022$ ). However, we found no significant associations of rs17875871 with chronic HBV disease $(p>0.05)$. Nevertheless, additional studies with a larger sample size are needed to verify this.
\end{abstract}

KEYWORDS: type I IFN receptor 1, hepatocellular carcinoma, SNP, rs2257167

\section{INTRODUCTION}

Hepatitis B virus (HBV) infection is a major global health problem. Approximately 350 million people worldwide are chronically infected with HBV. Some patients with chronic hepatitis B develop liver cirrhosis and hepatocellular carcinoma (HCC) leading to the death of approximately 1 million people each year ${ }^{1}$. Thailand has been considered to have intermediate endemicity of $\mathrm{HBV}^{2}$. Genetic factors are accepted as an important cause of chronic HBV infection, supported by the Chinese twin study ${ }^{3}$. Many host genetic factors have been discussed as potential causes of this disease such as human leucocyte antigen class I and II, cytokines, and cytokine receptor genes ${ }^{4}$.

The type I IFN receptor 1 (IFNAR1) is a receptor for interferon alpha and beta. The gene of IFNAR1 encoded a type I membrane protein that forms one out of two chains of the receptor. Its binding to type I IFNs stimulates the JAK-STAT signalling pathway leading to a second wave of type I IFNs creation ${ }^{5}$. IFNAR1 belongs to a cluster of class II cytokine receptor genes, identified as a major susceptibility locus ${ }^{6}$. Several studies showed the association between single nucleotide polymorphisms (SNPs) of the IFNAR1 gene with chronic HBV infection and/or the development of hepatocellular carcinoma (HCC) in Chinese and Vietnamese patients ${ }^{7-12}$. However, no significant association between IFNAR1 and chronic 
Table 1 Demographical characteristics and clinical profiles of subjects.

\begin{tabular}{lcccc}
\hline & $\begin{array}{l}\text { Healthy } \\
\text { subjects }\end{array}$ & $\begin{array}{c}\text { Self-limited } \\
\text { HBV infection }\end{array}$ & \multicolumn{2}{c}{ Chronic HBV infection } \\
\cline { 3 - 5 } & 136 & 176 & Without HCC & With HCC \\
\hline Number of subjects & $82 / 54$ & $93 / 83$ & $45 / 82$ & 128 \\
Gender (female/male) & $23 \pm 12$ & $48 \pm 14$ & $49 \pm 12$ & $27 / 101$ \\
Age (mean \pm SD) & NA & NA & $159 \pm 224$ & $51 \pm 20$ \\
ALT (U/1) (mean \pm SD) & NA & NA & $110 \pm 136$ & $57 \pm 48$ \\
AST (U/l) (mean \pm SD) & NA & NA & $5.5 \pm 1.8$ & $5.8 \pm 2.2$ \\
HBV DNA (log10) (mean \pm SD) & &
\end{tabular}

HBV, Hepatitis B virus; HCC, hepatocellular carcinoma; ALT, alanine aminotransferase; AST, aspartate aminotransferase; NA, not applicable.

HBV infection in Gambians was found in the study of Frodsham et $\mathrm{al}^{6}$. To confirm their findings, we explored the effects of IFNAR1 polymorphisms on chronic HBV infection and the development of HCC in a Thai population.

\section{MATERIALS AND METHODS}

\section{Subjects}

Two hundred and fifty-five Thai patients with chronic HBV infection from Chulalongkorn Memorial Hospital were recruited in this study. Serum HBV markers including HBsAg, anti-HBs, HBeAg, anti-HBe, and anti-HBc were measured in all patients. The diagnosis of chronic hepatitis B was established by seropositivity for HBsAg over a 6-month period. None of the patients were co-infected with hepatitis C virus, hepatitis D virus, or human immunodeficiency virus. All subjects did not have any other types of liver diseases such as nonalcoholic fatty liver disease, alcoholic liver disease, or drug-induced liver disease. In addition, all patients had elevated serum aspartate aminotransferase (AST), alanine aminotransferase (ALT) levels (> $40 \mathrm{U} / 1,1 \times$ upper limit of normal, ULN) and plasma HBV-DNA ( $>2000 \mathrm{IU} / \mathrm{ml}$ ). Patients with chronic HBV infection were further divided into two groups. The first group consisted of patients without HCC $(N=127 ; 45$ women and 82 men: mean age $\pm S D=49 \pm 12$ years) and the second group was patients with HCC $(N=128 ; 27$ women and 101 men: mean age $\pm S D=51 \pm 20$ years). Diagnosis of HCC was based on histopathology and/or a combination of mass lesions in the liver from hepatic imaging and serum alpha foetoprotein levels $>400 \mathrm{ng} / \mathrm{ml}$. In addition, a self-limited HBV group was used as a control containing 176 subjects (93 women and 83 men: mean age $\pm S D=48 \pm 14$ years) for which HBsAg was negative and both anti-HBc and anti-HBs were positive, with normal liver function tests, and no history of HBV vaccination. Additionally, 136 ethnically and geographically matched controls (82 women and 54 men: mean age $\pm S D=23 \pm 12$ years) from healthy blood donors of the Thai Red Cross Society were recruited as the healthy control group. This control group was also tested for HBsAg, anti-HBs, HBeAg, anti-HBe, anti-HBc and liver function. The ethics committee of the Faculty of Medicine, Chulalongkorn University, Bangkok, Thailand approved the study and the subjects gave their informed consent. Demographical characteristics and clinical profiles of subjects are shown in Table 1.

\section{DNA extraction and genotyping study}

DNA was extracted from the buffy coat collected with ethylenediaminetetraacetic acid (EDTA) as an anticoagulant, using the salting-out method ${ }^{13}$. DNA was aliquoted and stored at $-20^{\circ} \mathrm{C}$ until used. Polymerase chain reaction-restriction fragment length polymorphism (PCR-RFLP) was used to analyse the polymorphisms of IFNAR1 gene (rs2843710, G/C and rs2257167, G/C). The primer sequences were newly designed for this study. The forward primer for rs 2843710 was $5^{\prime}$-GGGCTCGAATTGTTTACTG - $3^{\prime}$ and the reverse primer was $5^{\prime}$-CTTGCTGACCCTAG AGTC $-3^{\prime}$. For rs2257167, the forward primer was $5^{\prime}$-GTGGGCTTTGGATGG-3' and the reverse primer was $5^{\prime}$-CCATGACGTAAGTAGTGC- $3^{\prime}$.

The PCR conditions were pre-denaturation at $94^{\circ} \mathrm{C}$ for $5 \mathrm{~min}$, followed by 35 cycles of denaturation at $94^{\circ} \mathrm{C}$ for $30 \mathrm{~s}$, annealing at $64^{\circ} \mathrm{C}$ (rs2843710) or $62^{\circ} \mathrm{C}$ (rs2257167) for $30 \mathrm{~s}$ and elongation at $72{ }^{\circ} \mathrm{C}$ for $30 \mathrm{~s}$, with a final elongation at $72^{\circ} \mathrm{C}$ for $5 \mathrm{~min}$. The PCR products were digested for $16 \mathrm{~h}$ with $B s i \mathrm{I}$ at $55^{\circ} \mathrm{C}$ for rs 2843710 and DdeI at $37^{\circ} \mathrm{C}$ for rs 2257167 . The digested PCR products were separated on 2.5-3\% agarose gel and visualized under UV light with ethidium bromide 


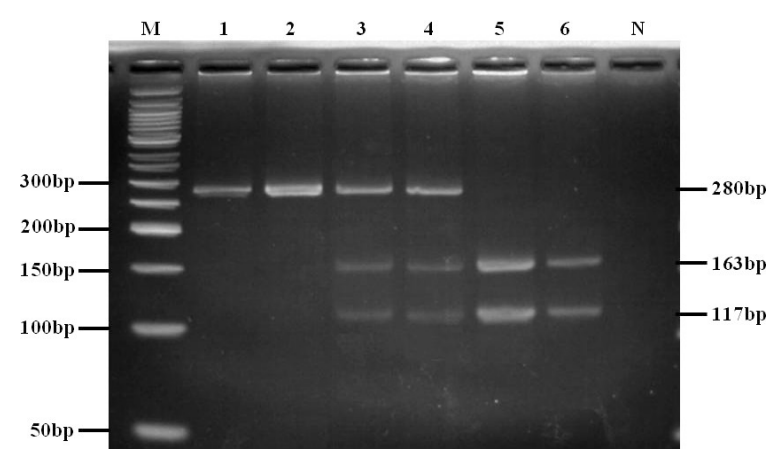

Fig. 1 The genotype analysis of SNP rs2843710 by the PCR-RFLP method. PCR products were digested with BslI. The CC homozygous showed a 280 bp uncleavage product (lanes 1 and 2), while the GC heterozygous showed $117 \mathrm{bp}, 163 \mathrm{bp}$ and $280 \mathrm{bp}$ cleavage products (lanes 3 and 4). The homozygous GG genotype yielded two bands in size of 117 and 163 bp (lanes 5 and 6). Lane M: 50 bp DNA Marker and lane N: negative control.

staining. In addition, a PCR single strand conformation polymorphism (SSCP) method was applied to study genotype polymorphism of rs17875871 (4-bp insertion/deletion) as previously described by Zhou et $\mathrm{al}^{9}$. Ten percent of the samples were confirmed by direct sequencing of PCR products to verify the accuracy of the genotyping.

\section{Statistical analysis}

Genotype frequencies were checked for consistency among normal controls with those expected from the Hardy-Weinberg equilibrium (HWE). The conditional logistic regression was used to investigate the association between SNPs and the outcome of the disease. PLINK program v1.07 program was used to calculate HWE, $p$ values, odds ratios (ORs) and 95\% confidence intervals (CIs), haplotype analysis as well as linkage disequilibrium (LD). $D^{\prime}$ value is preferred as a measure of $\mathrm{LD}$. The $D^{\prime}$ was determined by dividing $D$ by its maximum possible value, given the allele frequencies at the two loci $\left(D^{\prime}=\right.$ $\left.D / D_{\max }\right) . D^{\prime}=1$ is complete LD providing a useful indication of minimal historical recombination ${ }^{14}$. A $p$ value $<0.05$ was considered significant.

\section{RESULTS}

In this study, the polymorphism analysis of IFNAR1 gene was performed by PCR-RFLP and PCR-SSCP and the representative data are shown in Fig. 1, Fig. 2, and Fig. 3, respectively. As for rs 2843710 SNP, homozygous CC genotype yielded a single band of $280 \mathrm{bp}$, whereas GG genotype yielded two bands

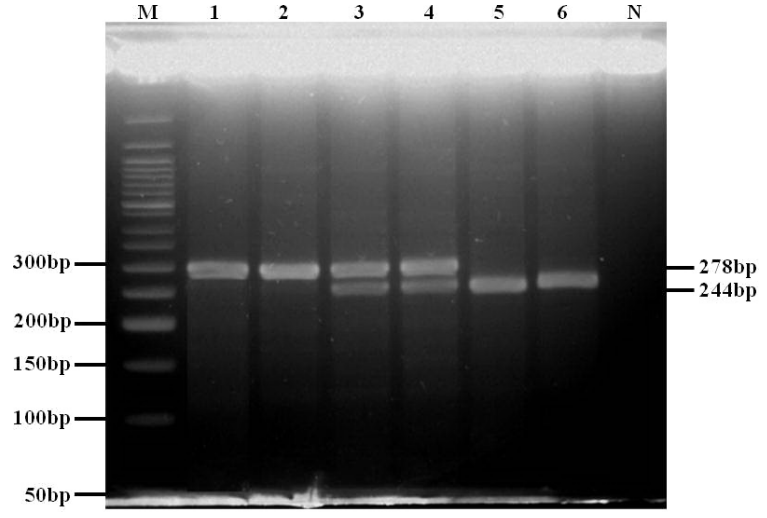

Fig. 2 The genotype analysis of SNP rs2257167 by the PCR-RFLP method. PCR products were digested with DdeI. The CC homozygous showed a 278 bp uncleavage product (lanes 1 and 2), while the GC heterozygous showed $34 \mathrm{bp}, 244 \mathrm{bp}$ and 278 bp cleavage products (lanes 3 and 4). The homozygous GG genotype yielded two bands in size of 34 and 244 bp (lanes 5 and 6). Lane M: 50 bp DNA Marker and lane N: negative control.

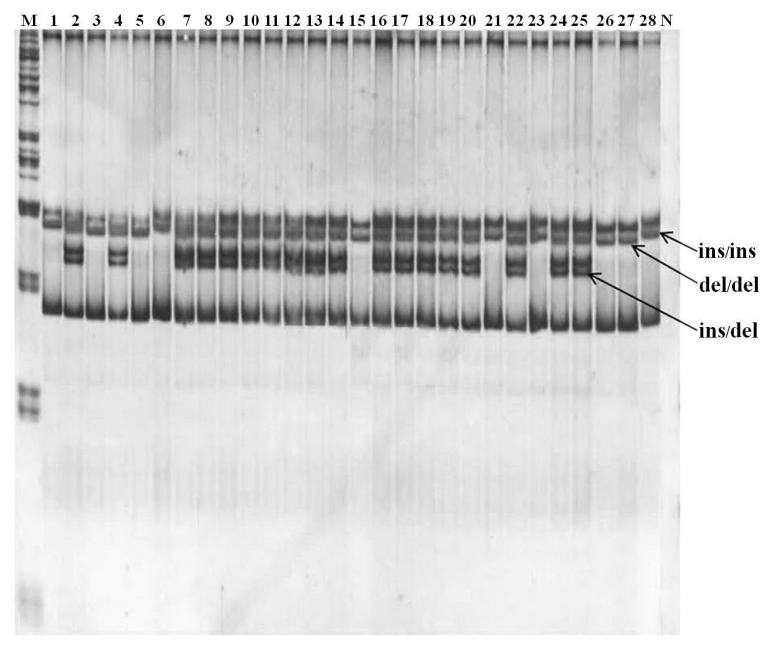

Fig. 3 Genotype patterns of rs17875871 by PCR-SSCP method. The PCR products were isolated by $7 \%$ polyacrylamide gel. The PCR product sizes were $179 \mathrm{bp}$ for deletion and $183 \mathrm{bp}$ for insertion (GAGA). The homozygous del/del genotype yielded two bands at lower levels (lanes 3,5,15,26,27), whereas ins/ins genotype yielded two bands at higher levels (lanes 1, 6, 21, 23, 28). Heterozygous ins/del genotypes yielded all four bands (lanes 2, 4, 7-14, 16-20, 22, 24, 25). Lane M: 50 bp DNA Marker and lane N: negative control.

of 117 and $163 \mathrm{bp}$. The heterozygous GC genotype showed three bands of $117 \mathrm{bp}, 163 \mathrm{bp}$, and $280 \mathrm{bp}$ cleavage products (Fig. 1). As for rs2257167, the 
Table 2 Genotype and allele frequencies of IFNAR1 gene polymorphisms in chronic HBV patients (with HCC and without HCC), self-limited HBV patients, and healthy controls.

\begin{tabular}{lcccccc}
\hline SNPs & $\begin{array}{c}\text { Genotype/ } \\
\text { allele }\end{array}$ & $\begin{array}{c}\text { Total chronic HBV } \\
N=255(\%)\end{array}$ & $\begin{array}{c}\text { HBV with HCC } \\
N=128(\%)\end{array}$ & $\begin{array}{c}\text { HBV without HCC } \\
N=127(\%)\end{array}$ & $\begin{array}{c}\text { Self-limited HBV } \\
N=176(\%)\end{array}$ & $\begin{array}{c}\text { Healthy control } \\
N=136(\%)\end{array}$ \\
\hline rs2843710 & GG & $26(10)$ & $9(7)$ & $17(13)$ & $17(10)$ & $25(18)$ \\
(G-568C) & GC & $136(53)$ & $80(63)$ & $56(44)$ & $96(55)$ & $66(49)$ \\
& CC & $93(36)$ & $39(30)$ & $54(43)$ & $63(36)$ & $45(33)$ \\
& G & $188(37)$ & $98(38)$ & $90(35)$ & $130(37)$ & $116(43)$ \\
rs2257167 & C & $322(63)$ & $158(62)$ & $164(65)$ & $222(63)$ & $156(57)$ \\
(G19158C) & GG & $89(35)$ & $39(30)$ & $50(39)$ & $53(30)$ & $36(26)$ \\
& GC & $128(50)$ & $75(59)$ & $53(42)$ & $87(49)$ & $67(49)$ \\
& G & $306(15)$ & $14(11)$ & $24(19)$ & $36(20)$ & $33(24)$ \\
rs17875871) & $153(60)$ & $153(60)$ & $193(55)$ & $139(51)$ \\
ins/del & in $/$ ins & $204(40)$ & $103(40)$ & $101(40)$ & $159(45)$ & $133(49)$ \\
& ins/del & $127(50)$ & $70(55)$ & $57(45)$ & $76(43)$ & $36(26)$ \\
& del/del & $52(20)$ & $26(20)$ & $26(20)$ & $39(22)$ & $67(49)$ \\
& ins & $279(55)$ & $134(52)$ & $145(57)$ & $198(56)$ & $139(51)$ \\
& del & $231(45)$ & $122(48)$ & $109(50)$ & $154(44)$ & $133(49)$ \\
\hline
\end{tabular}

HBV, hepatitis B virus; HCC, hepatocellular carcinoma; SNP, single nucleotide polymorphism.

CC genotype showed a 278 bp band of uncleavage product, the GG genotype showed $34 \mathrm{bp}$ and 244 bp bands, while the GC heterozygous genotype showed $34 \mathrm{bp}, 244 \mathrm{bp}$, and $278 \mathrm{bp}$ cleavage products (Fig. 2). As for rs 17875871 , the sizes of PCR products were $179 \mathrm{bp}$ for deletion and $183 \mathrm{bp}$ for insertion (GAGA). The homozygous del/del genotype yielded two bands at lower levels, whereas the ins/ins genotype yielded two bands at higher levels. Heterozygous ins/del genotype yielded all four bands (Fig. 3). Table 2 shows the distribution of genotype and allele frequencies of IFNAR1 polymorphisms (rs2843710, G-568C; rs2257167, G19158C; and rs17875871, 4-bp insertion/deletion GAGA) in chronic HBV patients (with HCC and without HCC), self-limited HBV patients, and healthy controls. In this study, all three SNPs were in HWE when comparing the observed and expected genotype frequencies of each SNP $(p>0.05)$. In the present study, the results showed a significant association between the GG genotype of rs 2843710 (G-568C) with a protective effect in chronic HBV infection when compared to GC and CC genotypes $(\mathrm{OR}(95 \% \mathrm{CI})=0.50(0.27-0.95), p=0.022)$. We also found that the GG genotype decreased in chronic HBV with HCC when we classified patients according to the presence or absence of HCC (OR $(95 \% \mathrm{CI})=0.34(0.14-0.79), p=0.006)$. For rs2257167 (G19158C), we found statistically significant differences in the allele frequency between patients with chronic HBV and healthy controls. The
G allele of this SNP was significantly associated with an increased risk in chronic HBV infection as compared to healthy individuals $(\mathrm{OR}(95 \% \mathrm{CI})=$ 1.44 (1.06-1.95), $p=0.017$ ). The effect of $\mathrm{G}$ allele was similar to the autosomal dominant in comparison of GG and GC genotypes to CC genotype (OR $(95 \% \mathrm{CI})=1.83(1.05-3.18), p=0.022)$. Our finding still showed a significant difference of $G$ allele of rs2257167 (G19158C) between chronic HBV patients with HCC and healthy controls as well as chronic HBV patients without HCC versus healthy controls (OR $(95 \% \mathrm{CI})=1.42(0.99-2.04)$, $p=0.045$ and $\mathrm{OR}(95 \% \mathrm{CI})=1.45(1.01-2.08)$, $p=0.035$, respectively). The autosomal dominant effect of G allele to chronic HBV patients with HCC was also found when compared to healthy controls $(\mathrm{OR}(95 \% \mathrm{CI})=2.61(1.26-5.45), p=0.004)$. However, the effect of $\mathrm{G}$ allele was similar to autosomal recessive model in chronic HBV patients without HCC when compared to healthy controls, in which the presence of GG genotype compared to GC and CC genotype conferred the OR $(95 \% \mathrm{CI})$ of 1.80 (1.04-3.14) and $p=0.026$. We did not find however any significant associations of rs 17875871 (4-bp insertion/deletion GAGA) in IFNAR1 gene between patients with chronic HBV and control groups $(p>0.05)$.

We also analysed the association of IFNAR1 haplotypes (rs2843710, G-568C and rs2257167, G19158C) with chronic HBV disease. Our study found an association between GG haplotype and the 
Table 3 Haplotype analysis for IFNAR1 rs2843710 (G-568C) and rs2257167 (G19158C).

\begin{tabular}{|c|c|c|c|c|c|c|c|c|c|c|}
\hline \multirow{3}{*}{$\begin{array}{l}\text { Haplo- } \\
\text { type }\end{array}$} & \multicolumn{4}{|c|}{ Haplotype frequency } & \multirow{2}{*}{\multicolumn{2}{|c|}{$\begin{array}{l}\text { Total HBV vs } \\
\text { healthy control }\end{array}$}} & \multirow{2}{*}{\multicolumn{2}{|c|}{$\begin{array}{l}\text { With HCC vs } \\
\text { healthy control }\end{array}$}} & \multirow{2}{*}{\multicolumn{2}{|c|}{$\begin{array}{l}\text { Without HCC vs } \\
\text { healthy control }\end{array}$}} \\
\hline & \multirow{2}{*}{$\begin{array}{c}\text { Total } \\
\text { chronic HBV }\end{array}$} & \multirow{2}{*}{$\begin{array}{l}\text { With } \\
\text { HCC }\end{array}$} & \multirow{2}{*}{$\begin{array}{l}\text { Without } \\
\text { HCC }\end{array}$} & \multirow{2}{*}{$\begin{array}{l}\text { Healthy } \\
\text { control }\end{array}$} & & & & & & \\
\hline & & & & & OR & $p$ value & OR & $p$ value & OR & $p$ value \\
\hline GC & 0.3162 & 0.3522 & 0.2759 & 0.4191 & 0.621 & $0.0041^{*}$ & 0.748 & 0.1330 & 0.538 & $0.0012^{*}$ \\
\hline $\mathrm{CC}$ & 0.0838 & 0.0502 & 2.1218 & 0.0699 & 1.150 & 0.6120 & 0.600 & 0.1890 & 1.670 & 0.0827 \\
\hline GG & 0.0524 & 0.0307 & 0.0784 & 0.0074 & 5.070 & $0.0239^{*}$ & 3.300 & 0.1490 & 6.100 & $0.0097^{*}$ \\
\hline CG & 0.5476 & 0.5670 & 0.5239 & 0.5037 & 1.220 & 0.1970 & 1.380 & 0.0859 & 1.100 & 0.5730 \\
\hline
\end{tabular}

HBV, hepatitis B virus; HCC, hepatocellular carcinoma; OR, odds ratio.

risk of chronic HBV infection (total chronic HBV: $\mathrm{OR}=5.070, p=0.0239$; chronic HBV without HCC: $\mathrm{OR}=6.100, p=0.0097$ ), while the GC haplotype seemed to be a protective haplotype (total chronic HBV: OR $=0.621, p=0.0041$; chronic HBV without HCC: $\mathrm{OR}=0.538, p=0.0012$ ) (Table 3 ).

\section{DISCUSSION}

We investigated the association between polymorphisms of IFNAR1 gene (rs2843710, rs2257167, and rs17875871) and the risk of chronic HBV infection. Our study found an association of IFNAR1 rs2257167 (G19158C) SNP with chronic HBV disease. The G allele of this SNP had a higher risk in the development of chronic HBV when compared to healthy individuals. The association of this $\mathrm{G}$ allele seems to be a dominant effect determined by model of inheritance analysis. Our results were consistent with a study of Zhou J et al, who found that the $\mathrm{G}$ allele was a susceptibility allele for chronic HBV infection ${ }^{11}$. The rs2257167 (G19158C) SNP is located on exon 4 and affect changing amino acids from Val (GTT) to Leu (CTT) at codon position 141 of IFNAR1 protein. Bioinformatics analysis revealed that Leu141 may influence the stability of the IFNAR1 structure greater than Val141. In addition, the study of Zhou $\mathrm{J}$ et al reported that the protein IFNAR1 expression levels on peripheral blood monocytes was higher in chronic HBV patients with a CC genotype (Leu141) than patients with a GG genotype (Val141) ${ }^{11}$. It is possible that chronic HBV patients carrying the G allele and/GG genotype decrease the stability of IFNAR1 protein on the cell surface and may affect ligand binding, leading to impaired antiviral response activity.

In addition, we divided chronic HBV patients into patients with HCC and without HCC groups. Our results showed that the G allele of rs2257167 (G19158C) SNP was associated with both groups as compared to healthy controls. However, no significant difference was found when we compared the patients with HCC to the without HCC group. This suggests that the rs2257167 polymorphism affects susceptibility to chronic HBV infection, but not the progression of HCC. Other polymorphisms may be responsible for the development of HCC. A recent study of Zhou $\mathrm{C}$ et al reported that a 4-bp insertion/deletion polymorphism (rs17875871) in the $3^{\prime}$ UTR of IFNAR1 affected the progression of HCC $^{9}$. This is in contrast to our finding that showed no significant relationship with the occurrence of HCC. This might be due to our limitations in a small sample size.

In this study, we also found an association between rs2843710 (G-568C) and chronic HBV infection. The GG genotype of rs2843710 (G-568C) seems to be a protective genotype when compare to GC and CC genotypes. This result was consistent with a study of Zhou J et al, who found that patients containing G allele and/or GG genotype were less susceptible to chronic HBV infection ${ }^{10}$. Although a correlation of G-568C SNP with chronic HBV infection was found, IFNAR1 promoter-luciferase reporter assay showed no significant difference between promoter variants between $-568 \mathrm{G} / \mathrm{G}$ and $\mathrm{C} / \mathrm{C}$ genotype ${ }^{10}$. Thus the persistence or clearance of HBV infection may be related to its linkage disequilibrium (LD) to other causative factors. Our study tested for linkage disequilibrium between rs2843710 (G-568C) with another SNP (rs2257167, $\mathrm{G} 19158 \mathrm{C})$. These two SNPs were in strong $\mathrm{LD}\left(D^{\prime}=\right.$ 0.829). Both were then analysed for association between haplotypes with chronic HBV disease. In the haplotype analysis, the association of IFNAR1 haplotypes (rs2843710, G-568C and rs2257167, G19158C) with chronic HBV was observed. The GG haplotype associated with the risk to chronic $\mathrm{HBV}$, whereas protective effect was found in GC haplotype. This finding supports the importance of another rs2257167 (G19158C) associated with chronic HBV infection in our study. However, $-568 / 19158$ haplotype analysis of Zhou $\mathrm{J}$ et al 
showed some different findings in that CG was a susceptible haplotype, while GC was a protective haplotype ${ }^{11}$. These controversial findings should be confirmed in further association studies.

In conclusion, our findings showed the association between IFNAR1 rs2257167 polymorphism and the risk to chronic HBV infection. Furthermore, the protective effect of rs 2843710 GG genotype was observed in this study. Nevertheless, a larger sample size should be utilized in further studies to probe the associations between the genotypes and the phenotypes.

Acknowledgements: This study was supported by the Thailand Research Fund (grants RMU5180051, MRG 5480191, and BRG5580005), the Faculty of Science and the Graduate School, Kasetsart University, the Kasetsart University Research and Development Institute (KURDI), and the Research Unit of Hepatitis and Liver Cancer, Chulalongkorn University.

\section{REFERENCES}

1. Lavanchy D (2004) Hepatitis B virus epidemiology, disease burden, treatment, and current and emerging prevention and control measures. $J$ Viral Hepat 11, 97-107.

2. Mohamed R, Desmond P, Suh DJ, Amarapurkar D, Gane E, Guangbi Y, Hou JL, Jafri W, et al (2004) Practical difficulties in the management of hepatitis B in the Asia-Pacific region. J Gastroenterol Hepatol 19, 958-69.

3. Lin TM, Chen CJ, Wu MM, Yang CS, Chen JS, Lin CC, Kwang TY, Hsu ST, et al (1989) Hepatitis B virus markers in Chinese twins. Anticanc Res 9, 737-41.

4. Thursz M, Yee L, Khakoo S (2011) Understanding the host genetics of chronic hepatitis B and C. Semin Liver Dis 31, 115-27.

5. de Weerd NA, Samarajiwa SA, Hertzog PJ (2007) Type I interferon receptors: biochemistry and biological functions. $J$ Biol Chem 282, 20053-7.

6. Frodsham AJ, Zhang L, Dumpis U, Taib NA, Best S, Durham A, Hennig BJ, Hellier S, et al (2006) Class II cytokine receptor gene cluster is a major locus for hepatitis B persistence. Proc Natl Acad Sci USA 103, 9148-53.

7. He XX, Chang Y, Jiang HJ, Tang F, Meng FY, Xie QH, Li PY, Song YH, et al (2010) Persistent effect of IFNAR-1 genetic polymorphism on the long-term pathogenesis of chronic HBV infection. Viral Immunol 23, 251-7.

8. Song le H, Xuan NT, Toan NL, Binh VQ, Boldt AB, Kremsner PG, Kun JF (2008) Association of two variants of the interferon-alpha receptor- 1 gene with the presentation of hepatitis B virus infection. Eur Cytokine Netw 19, 204-10.

9. Zhou C, Yu Q, Chen L, Wang J, Zheng S, Zhang J (2012) A miR-1231 binding site polymorphism in the
3'UTR of IFNAR1 is associated with hepatocellular carcinoma susceptibility. Gene 507, 95-8.

10. Zhou J, Lu L, Yuen MF, Lam TW, Chung CP, Lam CL, Zhang B, Wang S, et al (2007) Polymorphisms of type I interferon receptor 1 promoter and their effects on chronic hepatitis B virus infection. J Hepatol 46, 198-205.

11. Zhou J, Smith DK, Lu L, Poon VK, Ng F, Chen DQ, Huang JD, Yuen KY, et al (2009) A non-synonymous single nucleotide polymorphism in IFNAR1 affects susceptibility to chronic hepatitis B virus infection. $J$ Viral Hepat 6, 45-52.

12. Zhou J, Huang JD, Poon VK, Chen DQ, Chan CC, Ng F, Guan XY, Watt RM, et al (2009) Functional dissection of an IFN- a/b receptor 1 promoter variant that confers higher risk to chronic hepatitis B virus infection. J Hepatol 51, 322-32.

13. Miller SA, Dykes DD, Polesky HF (1988) A simple salting out procedure for extracting DNA from human nucleated cells. Nucleic Acids Res 16, 1215.

14. Purcell S, Neale B, Todd-Brown K, Thomas L, Ferreira MA, Bender D, Maller J, Sklar P, et al (2007) PLINK: a tool set for whole-genome association and population-based linkage analyses. Am J Hum Genet 81, 559-75. 